\title{
Automatic Transmission Fault Symptom Identification by Apply of Neural Network and D-S Evidence Theory
}

RyongSik O ${ }^{1}$, Jiangwei Chu², Zhenwei Sun ${ }^{2}$, Myongchol Ri ${ }^{3}$, MyongSu Sim ${ }^{1}$, Yongchol Kim ${ }^{1}$, SunGol Ryu', Chunlei Li ${ }^{2}$, CholSong Hwang ${ }^{1}$, KwangBok Kim ${ }^{1}$

${ }^{1}$ Department of Transport Mechanical Engineering, Pyongyang University of Mechanical Engineering, Pyongyang, 999093, Democratic People's Republic of Korea

${ }^{2}$ School of Traffic and Transportation, Northeast Forestry University, Harbin Heilongjiang, 150040, China

${ }^{3}$ Institute of Science, Pyongyang University of Mechanical Engineering, Pyongyang, 999093, Democratic

People's Republic of Korea

Article Info

Volume 8, Issue 3

Page Number : 778-799

Publication Issue

May-June-2021

\section{Article History}

Accepted : 12 June 2021

Published : 20 June 2021

\section{ABSTRACT}

At present, the method of identifying the fault symptoms of various machines by combining the neural network and the D-S evidence theory is attracting attention from researchers because the identification time is fast and the diagnosis is accurate. In this paper, it was mentioned a method for identifying the fault symptoms of automatic transmission by combining these two theories. First, it was mentioned a method for identifying fault symptoms of the automatic transmission by combining a fuzzy neural network and an RBF neural network. Next, it was newly described a method to improve the accuracy of fault symptom identification by the D-S evidence theory. In addition, the accuracy of this method was verified by an experimental method. In the experiment Firstly, two sub neural networks are established to recognize the initial symptoms. That is, the first sub-neural network E1 be used as the fuzzy neural network, the second sub-neural network E2 be used as RBF neural network, respectively, for preliminary symptom recognition. And then, these outputs of the two sub neural networks are used as the evidence space of D-S evidence theory, so the global diagnosis is carried out. The results show that the test results are consistent with the actual fault symptoms. The success rate of fault diagnosis up to $96.3 \%$, therefore, on the identification of the automatic transmission fault symptom, effectiveness, and feasibility of the D-S evidence theory based on information fusion is verified.

Keywords : D-S Evidence Theory, Symptom Identification, Fuzzy Neural Network, RBF Neural Network, Automatic Transmission 


\section{INTRODUCTION}

With the rapid development of automotive electronics technology, the proportion of electronic products in the automotive is larger and larger, the automotive has become, as a typical Mechatronics Products. Therefore, modern automobile fault diagnosis technology integrates modern diagnosis theory and advanced diagnostic technology and takes multi-function, electronic, intelligent, and integrated diagnosis equipment as the means, which becomes the technical guarantee for the realization of modern automobile reliability. In modern automobile fault diagnosis, we should research new theories and methods, and increase the research on information acquisition and fault characteristics. Artificial Neural Networks have proven effective in solving problems in a wide variety of areas, such as the fault diagnosis and working state monitor of aero-engine [1-3]. And it is widely applied in the last thirty years. The neural network system is a physical structure model of the neural network system of the human brain, that is, it stimulates the human brain from the physical structure by computer simulation method so that the system has some intelligence of the human brain. Artificial neural network by adjusting the weight corresponding to the learned samples, and master the relationship between the input and output. The relationship between the fault characteristics of actual structures and the dynamic response characteristics of structures is very difficult to be accurately described. But the neural network only needs to provide the corresponding output and input, no matter how complex the relationship can be easily learned. Neural networks can elicit rules from a large number of experimental data, and it is complex how these experimental data are imputed. From this, it has been widely applied fuzzy neural networks using the input of data that have undergone fuzzy preprocessing [4-6] It demonstrated that the robustness of the diagnosis system was enhanced by a fuzzy neural network [7]. Zhang found that FNN adopts a bi-directional association between fault symptoms and fault types, which was better than a one-way deduction from fault symptom to fault pattern [8]. It has been proven that ANN has the strongest self-learning ability among all the knowledge-based methods [2], and that fuzzy set theory coupled with ANN can handle any instability caused by imprecise and inaccurate information [9-11], so FNN can be chosen to train relationships between faults and symptoms in the machine diagnosis. Due to many advantages compared with other types of ANN, including better approximation ability, simpler network structure, and faster learning speed, radial basis function (RBF) neural network is continuously increasing its popularity in many fields [12]. RBF neural network was first proposed in the late 1980s [13, 14]. Normally, it forms a special architecture, which consists of three layers, namely input, hidden, and output layer. Each hidden layer node adopts a radial activated function, and output nodes implement a weighted sum of hidden unit outputs. Though many methods of fault diagnosis have been reported, each has its limitations [15]. In addition, though some advanced diagnostic methods have been proposed, fault diagnosis needs the decision of operators in practical applications. This kind of diagnosis is not autonomous, nor is it always accurate because it is based on experts' experience, and this may result in diagnostic errors. Some methods utilize information in the time domain only, while others use it in the frequency domain only [16]. From this, the fusion diagnosis method is widely used to resolve the inconsistency between data obtained through different domains or collection paths $[17,18]$. Because of the complexity of the device itself and running environment of instability, there are several uncertainties in the information reflecting the state of the equipment. These are the uncertainty of facts, the uncertainty of conditions in the rule, the uncertainty of the rule itself, the uncertainty of reasoning, and the uncertainty brought about by incomplete knowledge and data. The information fusion diagnostic method provides an effective means 
to deal with this uncertainty $[19,20]$. The $\mathrm{D}$ $\mathrm{S}$ (Dempster-Shafer) evidence theory is the decision method that is based on information fusion technology, D-S evidence theory is used as an effective means to find out the main faults with the maximum incidence by the combination of uncertain information. Therefore, it is widely used in machine diagnosis. In the automobile power-driven system, the automatic transmission is an important high-tech product that integrates mechanical, hydraulic, and electronic technologies. In the practice of its diagnosis, it is often used the following two methods. First, the diagnosis expert asks the user (driver) about the fault situation, visually inspects the vehicle, and according to his rich diagnosis experience, he initially judges the fault. Secondly, the diagnosis experts judge the fault symptoms through the real-time measurement data measured by the signal measuring instruments and the several sensors when driving directly. That is to say, the thinking process of the former stage is to recognize the driver's fuzzy language information according to the experience logic (thinking) of diagnostic experts, which can be considered to the thinking processing (qualitative identification) stage suitable for the fuzzy neural network. In addition, the thinking process of the latter stage is identified according to the quantitative analysis and judgment of the dynamic information measured in real-time, and it can be investigated to the thinking processing stage of the RBF neural network. According to the recognition method of fuzzy neural network and RBF neural network, the input signal is limited to various types, and the local diagnosis results are output.
Therefore, some results are similar to each other, and some results are different from each other. The purpose of diagnosis is to obtain the best diagnosis result and to maximize the accuracy of diagnosis by using the obtained diagnostic information. According to the decision method of D-S evidence theory, the local diagnosis results of these two neural networks are effectively used, and the uncertainty is reduced through the global combination, which improves the accuracy and reliability of the diagnosis.

\section{Fault symptom identification method based on fuzzy neural network in the automatic transmission}

\subsection{Fault symptom Identification based on Fuzzy Neural Network}

The diagnosis expert first determines the fault symptom according to the user's (driver's) appeal. Because the user's (driver's) appeal is the most important basis, so which refers to objective opinions of the fault is the first step of diagnosis. Therefore, first of all, according to the user's appeal to determine the fault symptoms. Diagnostic experts should determine what fault symptom it is according to their knowledge and experience.

According to the experience of experts, the standard fault symptoms of automatic transmission can be classified into eight standard symptoms as following (Table 1).

Table 1. Standard fault symptoms of automatic transmission (output parameter $y_{j}$ of fuzzy neural network)

\begin{tabular}{ccc}
\hline Number & Expert evaluation - Standard fault symptoms & output parameter, $\mathrm{y}_{\mathrm{j}}$ \\
\hline 1 & Abnormal starting in 1st shift & y1 \\
2 & It's impossible to drive range more than 1st shift & $\mathrm{y}_{2}$ \\
3 & Forwarding up from 1st shift to 2nd shift slow(slip) & $\mathrm{y}_{3}$ \\
4 & It's impossible to drive in drive range 3rd shift and 4th shift & $\mathrm{y}_{4}$ \\
5 & It's fixed in drive range 3rd shift and 4th shift & y5 \\
\hline
\end{tabular}




\begin{tabular}{lcl}
\hline 6 & The impact of shifting is strong & y6 \\
7 & The shift point (the speed when up-shifts and down-shifts) is too high & y7 \\
8 & Shifting off during driving (sudden downshift) & y8 \\
\hline
\end{tabular}

These eight standard fault symptoms can be decided according to the size of 16 kinds of state information (the appearing degree of fault phenomenon) by the user's appeal (Table 2).

Table 2. Fault phenomena and state information of automatic transmission (input parameter $\mathrm{x}_{\mathrm{i}}$ of fuzzy neur al network)

\begin{tabular}{lll}
\hline Number $\quad$ User appeal - fault phenomena and state information & input parameter, $\mathrm{x}_{\mathrm{i}}$ \\
\hline
\end{tabular}

1 The car's speed cannot exceed $20 \mathrm{~km} / \mathrm{h}$.

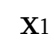

2 When the engine speed is more than $3000 \mathrm{r} / \mathrm{min}$, the car can barely start. $\quad \mathrm{x}_{2}$

3 If the temperature is low, it's only for 1 st shift, If the temperature rises, $\quad \mathrm{x}_{3}$ it is possible to upshift.

4 The start of moving is normal, but the shift can only be changed when $\quad \mathrm{x}_{4}$ the engine speed rises to a certain extent.

5 Fuel consumption is high.

6 The transmission does not maintain normal (sometimes it shifts by itself, $\quad$ x6 sometimes it does not shift).

7 The start of moving is delayed(It is only possible to move the car when engine speed is more than $1500 \mathrm{r} / \mathrm{min}$ )

8 It is difficult to increase the speed (above $40 \mathrm{~km} / \mathrm{h}$ ).

9 In the low state of the car's speed, the shifting is normal and is higher than the car's medium speed it is only rising engine speed.

10 When the engine speed is $3000 \mathrm{r} / \mathrm{min}$, car's speed cannot exceed $60 \mathrm{~km} / \mathrm{h}$. $\quad \mathrm{x}_{10}$

11 The start of moving is delayed, and it is impossible to shift $\quad \mathrm{x}_{11}$

12 On the uphill grade, the car doesn't traction well. $\quad \mathrm{X}_{12}$

13 Upshift is delayed. $\quad \mathrm{x}_{13}$

14 Only when the engine speed is high(more than $2500 \mathrm{r} / \mathrm{min}$ ), it is possible $\quad \mathrm{x} 14$ to upshift.

15 It seems to be in $\mathrm{N}$ shift during the drive the engine speed automobile $\mathrm{X} 15$

16 There is a feeling of gear shifting on the winding road or rough road $\quad$ X16

These user's appeals show very vague characteristics with his expression level. Diagnostic experts can identify standard fault symptoms based on this vague expression and their knowledge and experience. Once only the standard fault symptoms are identified, the diagnosis expert can determine the fault factors and causes of the fault symptoms according to the fault symptoms of the transmission and the fault factor correspondence table. Onthe "RE4R01A"typeautomatic transmission it provides therelationship between standard fault symptomsand c orresponding fault factors in Table 3. Thefault factors in Table3 are arranged in theorderof faultfrequency. In ot 
her words, the expert's thinking process for standard fault symptom recognition can bereplaced by a fuzzy neura 1 network. As shown in Figure1,first, we should befuzzed the user's response (status information) on the fault ph enomenon, this fuzzy processing is carried out based on fuzzy theory.

Table 3. Relationship between fault symptoms and corresponding fault factors

\begin{tabular}{|c|c|c|c|}
\hline № & fault symptoms & causes of fault (fault factors) & $\begin{array}{l}\text { inde } \\
\mathrm{x}\end{array}$ \\
\hline 1 & $\begin{array}{l}\mathrm{X}_{1} \text { : Abnormal starting in } \\
1 \text { st } \\
\text { shift }\end{array}$ & $\begin{array}{l}\text { Worn forward clutch } \\
\text { Seals of broken or worn in forward clutch } \\
\text { Unqualified assembly of Hydraulic control valve body } \\
\text { Unqualified assembly of the forward one-way clutch }\end{array}$ & $\begin{array}{l}\mathrm{S}_{4} \\
\mathrm{~S}_{8} \\
\mathrm{~S}_{14} \\
\mathrm{~S}_{5}\end{array}$ \\
\hline 2 & $\begin{array}{l}X_{2}: \text { It's impossible to drive } \\
\text { range more than 1st shift }\end{array}$ & $\begin{array}{l}\text { Worn forward clutch } \\
\text { Unqualified band brake } \\
\text { Unqualified overrun clutch } \\
\text { Unqualified 1- } 2 \text { shift valve in the hydraulic control valve body } \\
\text { Unqualified vehicle speed sensor } \\
\text { Unqualified governor valve }\end{array}$ & $\begin{array}{l}\mathrm{S}_{4} \\
\mathrm{~S}_{7} \\
\mathrm{~S}_{3} \\
\mathrm{~S}_{15} \\
\mathrm{~S}_{10} \\
\mathrm{~S}_{18}\end{array}$ \\
\hline 3 & $\begin{array}{l}\mathrm{X}_{3} \text { : Forwarding up from } 1 \mathrm{~s} \\
\text { t shift to 2nd shift slow(sli } \\
\text { p) }\end{array}$ & $\begin{array}{l}\text { Unqualified band brake } \\
\text { unqualified assembly }\end{array}$ & $\begin{array}{l}\mathrm{S}_{7} \\
\mathrm{~S}_{1}\end{array}$ \\
\hline 4 & $\begin{array}{l}\mathrm{X}_{4} \text { : It's impossible to drive i } \\
\mathrm{n} \text { drive range } 3 \text { rd shift and } \\
4 \text { th shift }\end{array}$ & $\begin{array}{l}\text { Unqualified overrun clutch } \\
\text { Seals of broken or worn in the overrun clutch } \\
\text { Lowfluid level or poor quality on the automatic transmissionflu } \\
\text { id } \\
\text { Unqualified oil temperature sensor }\end{array}$ & $\begin{array}{l}\mathrm{S}_{3} \\
\mathrm{~S}_{9} \\
\mathrm{~S}_{1} \\
\mathrm{~S}_{18}\end{array}$ \\
\hline 5 & $\begin{array}{l}\mathrm{X}_{5}: \text { It's fixed in drive range } \\
\text { 3rd shift and 4th shift }\end{array}$ & $\begin{array}{l}\text { Transmission ECU(fault, unqualified power supply, and groun-d } \\
\text { ing) } \\
\text { Each solenoid( broken wires, short) } \\
\text { Unqualified accelerator pedal sensor } \\
\text { Unqualified vehicle speed sensor } \\
\text { Unqualified range sensor }\end{array}$ & $\begin{array}{l}\mathrm{S}_{14} \\
\mathrm{~S}_{12} \\
\mathrm{~S}_{21} \\
\mathrm{~S}_{11} \\
\mathrm{~S}_{20}\end{array}$ \\
\hline 6 & $\begin{array}{l}\mathrm{X}_{6}: \text { The impact of shifting } \\
\text { is strong }\end{array}$ & $\begin{array}{l}\text { Rise of hydraulic line pressure ( hydraulic pressure control } \\
\text { solenoid or wire) } \\
\text { Unqualified 1- } 2 \text { shift valve in the hydraulic control valve body } \\
\text { Engine operation (high engine idle speed) } \\
\text { Worn forward clutch or overrun clutch } \\
\text { Unqualified accelerator pedal sensor } \\
\text { Unqualified vehicle speed sensor } \\
\text { Unqualified range sensor } \\
\text { Transmission ECU (fault, unqualified power supply, and groun-d } \\
\text { ing) } \\
\text { Broken in corresponding shift solenoid(fault, unqualified power }\end{array}$ & $\begin{array}{r}\mathrm{S}_{17} \\
\mathrm{~S}_{16} \\
\mathrm{~S}_{10} \\
\mathrm{~S}_{4,} \mathrm{~S}_{3} \\
\mathrm{~S}_{21} \\
\mathrm{~S}_{11} \\
\mathrm{~S}_{20} \\
\mathrm{~S}_{14} \\
\mathrm{~S}_{12}\end{array}$ \\
\hline
\end{tabular}




\begin{tabular}{|c|c|c|c|}
\hline & & supply, and grounding, short) & \\
\hline 7 & $\begin{array}{l}\mathrm{X}_{7} \text { : The shift point ( the spe } \\
\text { ed when up-shifts and dow } \\
\mathrm{n} \text {-shifts) is too high }\end{array}$ & $\begin{array}{l}\text { Unqualified accelerator pedal sensor } \\
\text { Worn forward clutch } \\
\text { Low hydraulic line pressure(worn oil pump, unqualified oil } \\
\text { filter) } \\
\text { Operation conditions(suddenly acceleration, tank deformation) } \\
\text { Unqualified vehicle speed sensor } \\
\text { Unqualified various control switches } \\
\text { Unqualified range sensor }\end{array}$ & $\begin{array}{l}\mathrm{S}_{21} \\
\mathrm{~S}_{4} \\
\mathrm{~S}_{15} \\
\mathrm{~S}_{2} \\
\mathrm{~S}_{11} \\
\mathrm{~S}_{13} \\
\mathrm{~S}_{20}\end{array}$ \\
\hline 8 & $\begin{array}{l}\mathrm{X}_{8} \text { : Shifting off during d } \\
\text { riving (sudden downshift) }\end{array}$ & $\begin{array}{l}\text { Unqualified forward one-way clutch } \\
\text { Unqualified accelerator pedal sensor } \\
\text { Seals of broken in corresponding shift solenoid } \\
\text { Transmission ECU(fault, unqualified power supply, and groun-d } \\
\text { ing) } \\
\text { Worn lockup clutch }\end{array}$ & $\begin{array}{l}\mathrm{S}_{5} \\
\mathrm{~S}_{21} \\
\mathrm{~S}_{22} \\
\mathrm{~S}_{14} \\
\mathrm{~S}_{6}\end{array}$ \\
\hline
\end{tabular}

In this way, afterfuzzy processing, the learning samples are completed more accuratelyand then input into the neural network so that it can correctly identify the standard fault symptoms.

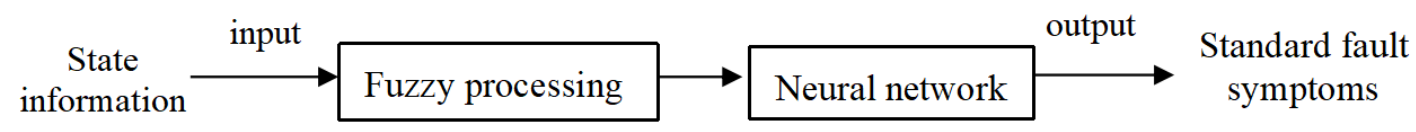

Figure 1. The series structure of the fuzzy neural network

\subsection{Fuzzification of input parameters}

Due to somekind of fault, in operating status, the change has occurred. The degree of uncertainty and fuzziness of the state information reflecting this amount of state change will be determined as the fuzzy membership degree. The fuzzy membership degree can be determined by communicating with experts from relevant departments and using fuzzy language variables. Fuzzy language variables are qualitative diagnostic variables that directly express the actual situation with their membership degrees [7]. According to the experience of field engineers, fuzzy language variables can be represented by the following fuzzy logic values:

$$
\left\{\begin{array}{c}
H=(0.7 / 0.8+0.9 / 0.9+1 / 1 \approx 1 \\
H s=(0.8 / 0.7+1 / 0.8+0.8 / 0.9) \approx 0.8 \\
M=(0.8 / 0.5+1 / 0.6+0.7 / 0.7) \approx 0.6 \\
L s=(1 / 0.3+0.8 / 0.4+0.7 / 0.5) \approx 0.3 \\
L=(1 / 0+0.7 / 0.1+0.6 / 0.2) \approx 0
\end{array}\right.
$$

If the probability of occurrence of the fault phenomenon is expressed as the fuzzy language variable, its degree of membership is equal to Table 4. Ordinary users who lack the concept of numbers and have low functions can easily use the diagnosis of fuzzy language variables, which has the advantage of expressing a more correct state. 
Table 4. Degree of membership on the fuzzy language variable

\begin{tabular}{l|c|c}
\hline \multicolumn{1}{c|}{$\begin{array}{c}\text { probability of occurrence on the fault } \\
\text { phenomenon }\end{array}$} & fuzzy language variable & $\begin{array}{c}\text { degree of } \\
\text { membership }\end{array}$ \\
\hline appear obviously, & H & 1 \\
appear & Hs & 0.8 \\
Appear to a certain extent & M & 0.6 \\
A little appear & Ls & 0.3 \\
Don't appear & L & 0 \\
\hline
\end{tabular}

If the user's state quantity information is used as an input indicator and expressed as $X$, then each input parameter $\mathrm{X}$ containing every 16 states can be expressed as $\mathrm{X}\left(\mathrm{X}_{1}, \mathrm{X} 2, \mathrm{X}_{3}, \ldots \mathrm{X}_{16}\right)$. If the standard fault symptoms are expressed by the output parameter, the output parameter $\mathrm{Y}$ including 8 standard fault symptoms can be expressed by $\mathrm{Y}\left(\mathrm{Y}_{1}, \mathrm{Y} 2, \mathrm{Y}_{3}, \ldots \mathrm{Y}_{8}\right)$. Therefore, we can make the fuzzy rule base in which the status information of the fault phenomenon is used as the input parameter, and the standard fault symptom is used as the output parameter.

\subsection{Design of Neural network}

The neural network uses BP neural network as a three-layer structure (Figure 2)

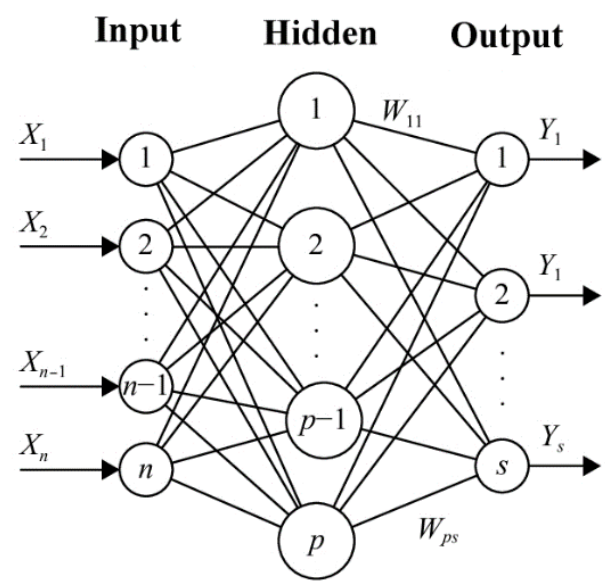

Figure 2. Topology structure of BP neural network

In the BP neural network, if the number of nods in the input layer increases, the learning time will be delayed, and it is easy to converge to a local minimum. To overcome these shortcomings, it is used the momentum operator and the learning rate change algorithm to modify the weight coefficient.

$$
\Delta \omega(k+1)=-\eta \frac{\partial E(k)}{\partial \omega(k)}+\alpha \omega(k)
$$

Where $\omega(k)$ : in the $k$ th learning stage, the combined weight coefficient $\omega$ of the nodes between the layers, $\Delta \omega(k)$ : in the $k$ th learning stage, the correction value of combined weight coefficient $\omega$ of the nodes between the layers, $E(k)$ : in the $k$ th learning stage, the square deviation between the output of the network and the actual value, $\eta$ : the learning rate in the $k$ th learning stage, $\alpha$ : the momentum operator in the $k$ th learning 
stage. The number of nods in the input layer is determined as the number of inputs on the 16 types of fault state of transmission which previously determined, and the output layer is determined as the number of standard fault symptoms which previously determined, the number of node in the hidden layer is generally determined in the following equation. According to the Kolmogorov equation of determining the number of nodes in the hidden layer, the number $\mathrm{n}_{2}$ of nods in the hidden layer is as follows.

$$
\mathrm{n}_{2}=2 \mathrm{n}_{1}+1
$$

Where $\mathrm{n}_{1}$ : The number of nodes in the input layer, that is, $\mathrm{n}_{1}=16$. The number of nods in the hidden layer is not certain and continues to be adjusted and confirmed through the inspection of the learning process. Throughout inspection and adjustment, it is adopted $\mathrm{n}_{2}=28$ in the given fuzzy fault Symptom Identification neural network. In other words, it is constructed with a 16-28-8 network structure, and the fuzzyneural networkistrained using input and output sample data to create a fuzzy fault symptomrecognition rule base.

\section{Fault symptom identification method based on RBF neural network in the automatic transmission}

Generally, the diagnosis experts personally identify the fault symptom by driving on the road. The purpose of the driving test is to determine the standard fault symptoms by confirming the shifting point (vehicle speed at the upper and lower shifting) and the shock, vibration, noise, and slippage during shifting. The content of the driving test includes the inspection of starting performance, acceleration performance, shifting performance, shifting timing, and shifting quality. These quantitative analyses and evaluations of experts can be modeled as an RBF neural network (Radial Basis Function Neural Network). Figure 3 shows this modeling.

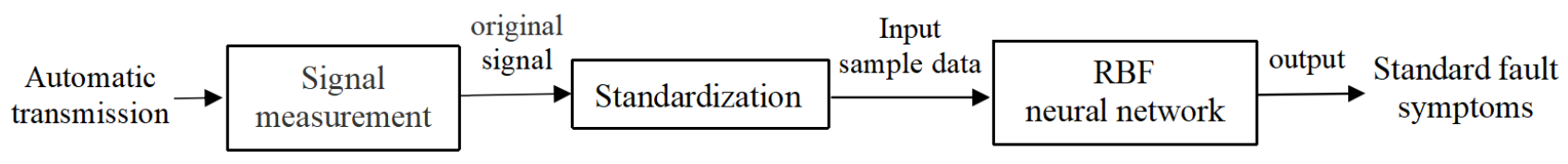

Figure 3. Structure of fault symptom identification system based on real-time measurement of dynamic state

\subsection{Measuring operating status}

Using the OBD-II measuring device, take real-time measurements on the engine speed signal, throttle position signal, vehicle speed signal, transmission oil temperature signal, shift valve signal, and shift range signal during the drive, and convert them into digital signals so that its input to a computer. Table 5 shows the operation parameters of the normal operation process of the automatic transmission through real-time control.

Table 5. Measurement results of real-time operating parameters of automatic transmission under normal conditions

\begin{tabular}{lcccccc}
\hline \multicolumn{1}{c}{ Measurement } & \multicolumn{6}{c}{ Shift solenoid signal, i } \\
of operation parameters & 1 & 2 & 3 & 4 & 5 & \\
\hline engine speed, $\mathrm{N}(\mathrm{rpm})$ & 1700 & 2000 & 2005 & 2010 & 2020 \\
vehicle speed , $\mathrm{V}(\mathrm{Km} / \mathrm{h})$ & 18.5 & 37.5 & 52.5 & 75 & 85 \\
throttle position signal, $\mathrm{T}(\%)$ & 21 & 21.5 & 22 & 23 & 24 \\
\hline
\end{tabular}


In the fault state of the automatic transmission, these operating parameters show various changes. It is identified standard fault symptoms based on the quantitative analysis of these operating parameters. These information-processing stages can be considered as thinking processing stages of the RBF neural network. That is, first it is should collect the real-time information detected by some sensors of the automatic transmission electronic control system and then input them into the RBF neural network so that it identifies fault symptoms.

\subsection{Standardization of detected operating parameters}

If you want to input the real-time measured state values into the neural network, you must first use the extreme standardization method to standardize. In the whole process of measurement, all measurement values are entered into the group of the closest classification set point. At the same time, the center point of each group is recalculated and the original set point is corrected. Where $x_{i j}$ is called the $j$ th parameter of the $i$ th state, If it is $M A=\max _{1<i<n_{i}} x_{i j} M I=\min _{1<i<n_{i}} x_{i j}$, when every sample is divided into $K$ groups, the group to which $x_{i j}$ belongs is expressed as $k(j)$, and it is as follows.

$$
k(j)=\frac{(K-1)\left(x_{i j}-M I\right)}{(M A-M I)}, \quad 1<k<K
$$

Each classification set point is a representative point that reflects a set of values, namely numerical centers. The state value of each $k$ th classification set point is standardized by the extreme standardization method.

$$
x_{k j}^{\prime}=\frac{\left(x_{k j}-x_{\max j}\right)}{\left(x_{\max j}-x_{\min j}\right)}
$$

Where $x_{k j}^{\prime}$ : Standardized the $j$ th state value of the $k$ th classification set point, $x_{\max j}, x_{\min j}$ : The maximum and minimum values of the values $\left\{x_{1 j}, x_{2 j}, x_{3 j}, \ldots . . x_{K j}\right\}$

\subsection{Fault symptom identification method based on RBF neural network}

To classify correctly the real-time changing of state values, a special form neural network suitable for thisradial basis neural network, namely RBF neural network is used to improve the effect and accuracy of diagnosis. The radial basis neural network (RBF) is a kind of neural network structure submitted by J. Moody and C. Darken in the late 1980s of the 20th century, it is superior to the BP neural network in terms of function approximation ability, classification ability, and learning speed. The RBF neural network uses the Radial Basis Function of multivariate interpolation in multidimensional space. The topology structure of the RBF neural network is shown in Figure 4.

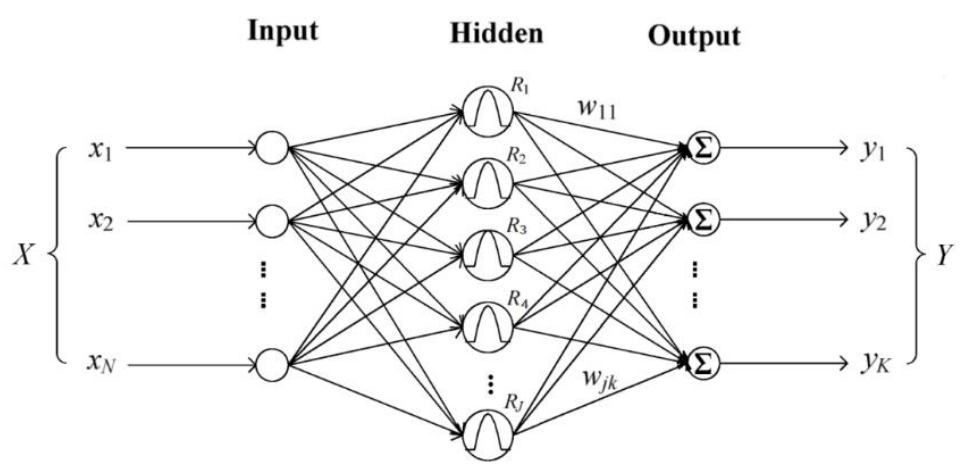

Figure 4. Topology structure of the RBF neural network. 
As shown in Figure 4. a typical RBF neural network has three layers: the input layer, the hidden layer, and the output layer, all layers perform different roles. The first layer is an input layer composed of sensory nods, and the number of input nods is equal to the number of the argument of the object being studied. The second layer is the hidden layer of the RBF function neural nod, it is formed by the non-linear transformation that transmits the input signal to the hidden layer through the weight coefficient between the input layer and the hidden layer of the network. The number of neural nods in the hidden layer depends on the problem being described. The transfer function of the RBF neural node has several forms, the most commonly used is the Gaussian function (radbas). The structure of the RBF neural node is shown in Figure 5.

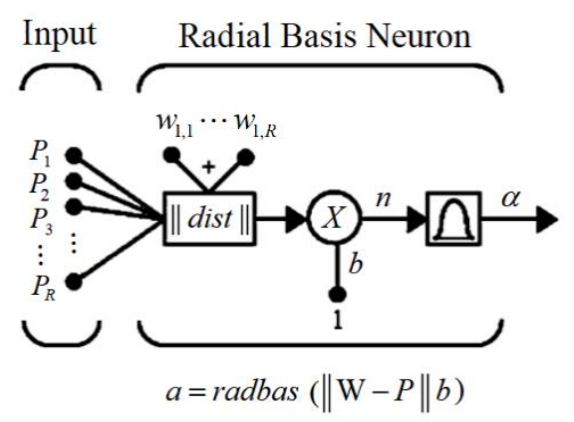

Figure 5. Structure of the RBF neural node

$i$ th node of the hidden layer is defined as follows:

$$
q_{i}=R\left(\left\|X-c_{i}\right\|\right)=\exp \left(-\frac{\left\|X-c_{j}\right\|}{2 \sigma^{2}}\right)
$$

Where $X$ : the n-dimensional input vector, $\boldsymbol{C}_{i}$ :the center of the $i$ th node of the hidden layer, $\left\|X-c_{j}\right\|:$ the norm of the vectors $X$ and $C_{i}$ in the n-dimensional space, which can also be regarded as the distance between the vectors $X$ and $C_{i}, R(\square)$ : Gaussian function. A Gaussian function is a non-linear function that decreases symmetrically at the central point of a kind of local distribution and has the non-linear mapping ability of the RBF neural network (Figure 6).

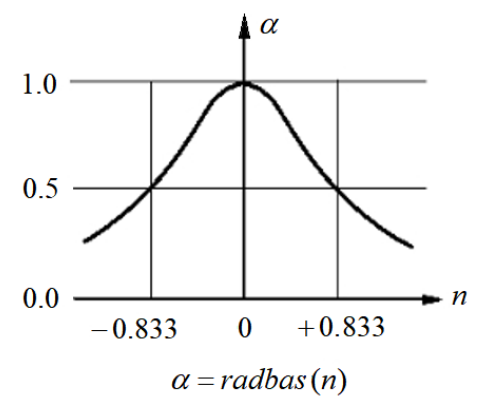

Figure 6. Graph of Gaussian function

As shown in Figure 6, when $\mathrm{n}$ is 0 , the RBF function outputs the maximum value 1 . That is, when the distance between the weight vector $\mathrm{w}$ and the input vector $\mathrm{p}$ decreases, the output increases. In other words, the Gaussian function has a strong ability to respond locally to input information. Since the hidden layer neural nods are composed of a Gaussian function, it causes an extreme response to the transmission of an input signal. 
The third layer is the output layer, and the output layer neural nodes consist of a weighted summation of all outputs of the hidden layer. It represents the response to the action of the input model. The output of the $l$ th node of the output layer is as follows.

$$
y_{l}=\sum \omega_{l i} q_{i}-\theta_{l}
$$

Where $\omega_{l i}$ : weight coefficient of the linear mapping from $q_{i}$ to $y_{l}, \theta_{l}$ : threshold of $l$ th output node.

Finally, in the RBF neural network, the mapping from the input information $X=\left(x_{1}, x_{2}, x_{3}, \ldots . . x_{n}\right)$ detectedin real-ti me to the output $Y=\left(y_{1}, y_{2}, y_{3}, \ldots . . y_{l}\right)$ is obtained. The variables to be input to the RBF neural network are the eng ine speed $\mathrm{N}(\mathrm{rpm})$, the vehicle speed $\mathrm{V}(\mathrm{Km} / \mathrm{h})$, and throttle position signal $\mathrm{T}(\%)$ at each shift $\mathrm{i}$. In the case of a 5 -speed transmission, if measurement parameters of $5^{*} 3=15$ are inputvariables, the number of nodes in the input layer is 15 . If the standard fault symptoms of the given transmission are classified into 8 groups, the number of nodes in the output layer is 8 . When design an RBF neural network using MATLAB, use the newrb function. Th e newrb function sets the number of RBF neural nodes equal to the number of nodes in the input layer. An RB $F$ neural network of 15-15-8 network structure was trained with the learning samples detected during the mult i metering so that it is created an RBF fault symptom identification network.

\section{Method to improve the accuracy of automatic transmission fault symptom identification based on D-S evidence theory}

In the identification method of fuzzy neural network and RBF neural network, because the characteristics of input signals are different, so identification results obtained through different paths are different from each other. The purpose of fault diagnosis is to obtain an optimal diagnosis result and to maximize the accuracy of diagnosis by using the obtained diagnosis information. D-S (Dempster-Shafer) evidence theory is used as an effective means to find the fundamental fault cause with the maximum probability of happening by combining inaccuracy information. In the two identification methods mentioned above, the input signals are limited to different types and output local identification results, so some results are approximate to each other and some results have certain deviations from each other. The decision method based on the D-S evidence theory effectively utilizes the local identification results output from these two sub-neural networks to reduce uncertainty and improve the accuracy and reliability of diagnosis through a global combination. As shown in Figure 7, the identification results of two neural networks make up of $E_{1}$ and $E_{2}$ which is the evidence space of the D-S evidence theory, Then, each identification result becomes a piece of evidence in the given evidence space.

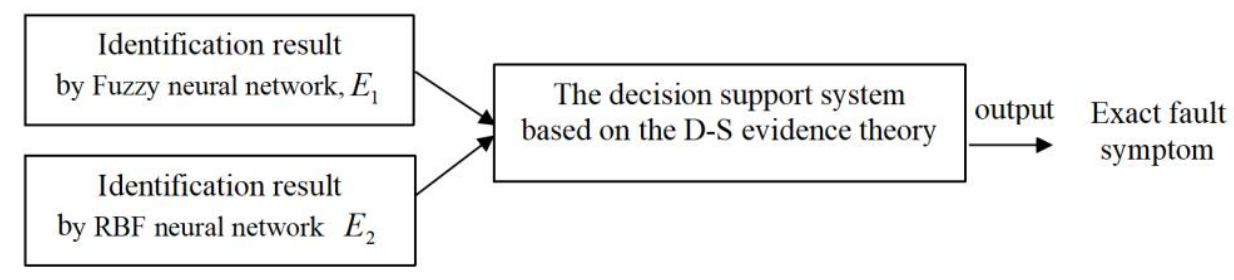

Figure 7. Fault symptom Identification system based on the sub-neural networks and D-S evidence theory 
The reliability of the global identification result by the composite rule of the D-S evidence theory is much greater than the reliability of the local identification result of each sub-neural network. Therefore, it is possible to overcome the identification error created by inaccuracy when performing symptom identification using sub-neural networks.

\subsection{Information fusion process and symptom identification of D-S evidence theory}

(1) First, let the identification state set to be identified by the diagnostic system be $A$, and it is indicated by $A=\left\{A_{1}, A_{2}, \cdots A_{t}\right\}$. Where $t$ is the number of identification state set.

(2) When a sub-neural network $E_{1}, E_{2}, \cdots E_{s}$ exists, a basic belief function $m_{k}\left(A_{j}\right)$ and non-accurate belief function $m_{k}(\theta)$ are calculated for each identification state of each identification space $E_{k}$.

(3) Each sub-neural network $E_{k}$ separately calculates a basic belief interval $\left[\operatorname{Bel}_{k}\left(A_{j}\right), \operatorname{Pl}_{k}\left(A_{j}\right)\right]$ for each state of the identification state set.

Let $\operatorname{Bel}(A)$ be belief of $A$, and let $P l(A)$ be plausibility of $A$, and it denoted by $P l(A)=1-\operatorname{Bel}(\bar{A})$. Where $\operatorname{Bel}(\bar{A})$ indicates the degree to which $A$ is not, in other words, it represents the degree of the unbelief of $A$. At this time, the belief interval $[\operatorname{Bel}(x), P l(x)]$ of $A$ is divided into a support interval and a nondeterministic interval as shown in Figure 8, and it divides the upper and lower relationships of belief of $A$.

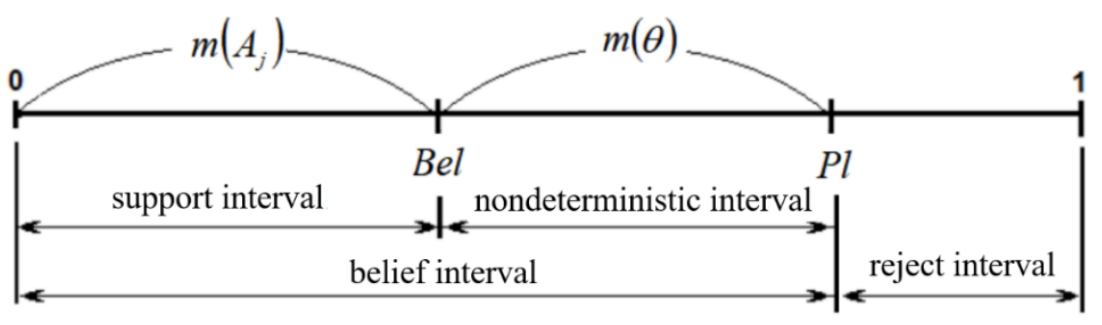

Figure 8. The divide of belief interval

(4) Using the composite rule of the D-S evidence theory, the basic probability assignments $m\left(A_{j}\right)$ are obtained under the composite action of all sub-neural networks, Among them, selected the one which it is $m\left(A_{j}\right)>0.5$ and maximum value, and it is $m(\theta)<0.25$, and then it is determined as the final identification result. In this way, it is more reliable because the diagnosis result is obtained by sufficiently drawing out the fault characteristics included in each fault state through the global combination of the sub-neural networks and the D-S evidence theory.

\subsection{Calculation on the belief}

1) Norm and correlation scale

The characteristic vectors of the monitoring parameters obtained in the $i$ th sub-neural network $E_{i}$ of evidence space $E$ are denoted by $X_{i}=\left\{x_{i 1}, x_{i 2}, x_{i 3}, \cdots x_{i t}\right\}$. In the identification set $A$, the state values of each element of the $i$ th sub-network corresponding to each classification state $A_{j}$ are called monitoring vectors and denoted by $x_{i, j}$. Also, the corresponding normal vector is the $t \times t$ unit matrix which is $Y_{i}=\left\{y_{j 1}, y_{j 2}, y_{j 3}, \cdots y_{j t}\right\}$. 
(1) Euclidean norm between the monitoring vector $X_{i}$ and the normal vector $Y_{i}$ is as follows.

$$
d_{i j}\left(x_{i,} y_{j}\right)=\sum_{k=1}^{t}\left|x_{i k}-y_{j k}\right|, i=\overline{1,2}, j=\overline{1, t}
$$

Where $d_{i j}$ indicates the degree of approximation between the $i$ th sub-network and each $A_{j}$ of identification set A, so the larger the $d_{i j}$, the lower the degree of approximation. Conversely, the smaller the $d_{i j}$, the greater the degree of approximation.

(2) It defines the correlation coefficient between the $i$ th sub-neural network and each state $A_{j}$

$$
C_{i}\left(A_{j}\right)=\frac{1}{d_{i j}} \sum_{j=1}^{t} \frac{1}{d_{i j}}
$$

(3) It defines the maximum correlation coefficient $\alpha_{i}$ between the $i$ th sub-neural network and all states

$$
\alpha_{i}=\max _{j} C_{i}\left(A_{j}\right)
$$

2) It defines the distribution coefficient $\beta_{i}$ of the relationship between the $i$ th sub-neural network and each state $A_{j}$

$$
\beta_{i=} \frac{t \alpha_{i}}{\sum_{j=1}^{t} C_{i}\left(A_{j}\right)}-1
$$

3) It defines the belief coefficient $\boldsymbol{R}_{i}$ of the $i$ th sub-neural network in the system.

$$
R_{i}=\alpha_{i} \beta_{i} / \sum_{i=1}^{s} \alpha_{i} \beta_{i}
$$

Where s: the number of evidences (in this test, $s=2$ ). Since the accuracy of each diagnostic path is different in the fusion process of the output data of several sub-neural networks, each sub-network shows a different belief. Therefore, in determining the belief function, the belief coefficient $R_{i}$ is introduced to increase the accuracy of the decision.

4) determination of probability assignments

(1) In the $i$ th sub-neural network the probability assignments $m_{i}\left(A_{j}\right)$ of state $A_{j}$ is as follows.

$$
m_{i}\left(A_{j}\right)=\frac{C_{i}\left(A_{j}\right)}{\sum_{j=1}^{t} C_{i}\left(A_{j}\right)+2\left(1-R_{i}\right) \cdot\left(1-\alpha_{i} \beta_{i}\right)}
$$

(2) The probability assignments $m_{i}(\theta)$ of inexact $\theta$ in evidence groups $E$ is as follows.

$$
m_{i}(\theta)=\frac{s\left(1-R_{i}\right)\left(1-\alpha_{i} \beta_{i}\right)}{\sum_{j=1}^{t} C_{i}\left(A_{j}\right)+s\left(1-R_{i}\right)\left(1-\alpha_{i} \beta_{i}\right)}
$$

Let the probability assignments corresponding to each identification state of the network $E_{1}$ be $m_{1}\left(A_{1}\right), m_{1}\left(A_{2}\right), m_{1}\left(A_{3}\right) \cdots m_{1}\left(A_{t}\right)$. Let the probability assignments corresponding to each identification state of the network $E_{2}$ be $m_{2}\left(A_{1}\right), m_{2}\left(A_{2}\right), m_{2}\left(A_{3}\right) \cdots m_{2}\left(A_{t}\right)$.

\subsection{Combination of probability assignments}

Bel $\mathbf{l}$ and $\mathrm{Bel}_{2}$ are probability assignments in the identification set A of sub-networks. If there are two sub- 
neural networks, $m_{1}$ and $m_{2}$ is the corresponding basic probability assignments, therefore, if it is $m(A)>0$, $A$ is called as the central element. When the states of the two sub-networks are denoted by $A_{1}, A_{2}, A_{3} \cdots A_{t}$ and $B_{1}, B_{2}, B_{3} \cdots B_{t}$ respectively, if is $\sum m_{1}\left(A_{i}\right) m_{2}\left(B_{j}\right)<1$, combined basic probability assignments is as follows.

$$
\begin{array}{ll}
m(A)=\frac{\sum_{A_{i} \cap B_{j}=U} m_{1}\left(A_{i}\right) \cdot m_{2}\left(B_{j}\right)}{1-\sum_{A_{i} \cap B_{j}=\Phi} m_{1}\left(A_{i}\right) \cdot m_{2}\left(B_{j}\right)}, & A \neq \Phi \\
m(\theta)=\frac{\sum_{A_{i} \cap B_{j}=U} m_{1}(\theta) \cdot m_{2}(\theta)}{1-\sum_{A_{i} \cap B_{j}=\theta} m_{1}\left(A_{i}\right) \cdot m_{2}\left(B_{j}\right)}, & A \neq \Phi
\end{array}
$$

Using equations (12) and (13), it calculates the probability assignments corresponding to each identification state in the whole system, respectively. Through this information fusion, it is calculate the $m\left(A_{j}\right)$ and $m(\theta)$ so that the fault probability of each state in the whole diagnostic system is determined, and standard fault symptoms which is $m\left(A_{j}\right)>0.5$ and $m(\theta)<0.25$ are determined as the final identification result.

\section{Experimental verification}

\subsection{Experimental analysis procedure}

(1) Two cars of the same type with abnormal automatic transmission operation are selected as subjects for exper imental verification and, first, fault symptoms are identified by the fuzzy neural network according to the drive r's appeal.

(2) Connect the OBD-II measuring device to the same test subject and input the measurement signals that chan ge in real-time through the driving test to the computer so that it identifies the fault symptoms by the RBF neu ral network.

(3) Using the two identification results above, it is formed the evidence space of the D-S evidence theory, and t he corresponding fault symptoms are confirmed based on the D-S evidence theory.

(4) After determining the fault factor and cause corresponding to the fault factors relationship table according $t$ o the standard fault symptoms already confirmed according to the expert database, disassemble and inspect the corresponding element and repair it. That is, the accuracy of the fault cause determination by this fault sympto $m$ identification system is verified.

\subsection{Fault symptom identification experiment by fuzzy neural network}

In the experiment, standard fault symptoms were identified for different fault phenomena of two «RE4R01A» type automatic transmissions. Fault symptoms were identified by the fuzzy neural network ofthe already prepared 16-28-8 system. Prepare input parameters $X_{1}$ and $X_{2}$ through fuzzy processing according to driver's appeal for different fault phenomena of two 《RE4R01A》 type automatic transmissions. Since the state parameters are marked with $X=\left(x_{1}, x_{2}, x_{3}, \ldots . . x_{16}\right)$, the sample values that have undergone fuzzy processing according to the driver's appeal are as follows. 


$$
\begin{aligned}
& X_{1}=(0,0,0,1,0.6,0,0.6,0.6,0.3,1,0,0,0.3,0.3,0,0) \\
& X_{2}=(0,0,0,0.8,0.6,0,0.6,0,0.3,0.3,0,0,0.6,1,0,0)
\end{aligned}
$$

Table 6 shows the standard fault identification results of the fuzzy neural network for these two test samples.

Table 6. Standard fault symptom identification results table for test samples

\begin{tabular}{c|c|c|c|c|c|c|c|c}
\hline \multirow{2}{*}{ Test subject } & \multicolumn{7}{c}{ identification results } \\
\cline { 2 - 9 } & $y_{1}$ & $y_{2}$ & $y_{3}$ & $y_{4}$ & $y_{5}$ & $y_{6}$ & $y_{7}$ & $y_{8}$ \\
\hline 1 & 0.0072 & 0.1018 & 0.0474 & 0.0431 & 0.3131 & 0.3442 & 0.7835 & 0.3214 \\
\hline 2 & 0.1314 & 0.6017 & 0.0703 & 0.2404 & 0.2813 & 0.0317 & 0.0801 & 0.0516 \\
\hline
\end{tabular}

As the fuzzy neural network identification result shows, the standard fault symptoms with the highest incidence are $\mathrm{y}_{3}=0.797$ for the first object and $\mathrm{y}_{8}=0.783$ for the second object. Therefore, the 3rd and 8 th symptoms on the 1st and 2nd test subjects can be judged as corresponding standard fault symptoms, respectively.

\subsection{Fault symptom identification experiment by RBF neural network}

Through the driving test on the same test subject as before, the amount of state change of the transmission was measured in real-time, and using them it were identified fault symptoms by the RBF neural network. Table 7 shows the original signals and standardized data samples measured during the driving test.

\begin{tabular}{|c|c|c|c|c|c|c|c|c|c|c|c|c|c|c|c|}
\hline \multirow{2}{*}{ number } & \multicolumn{15}{|c|}{ Status values of the test subjects } \\
\hline & $\mathrm{N}_{1}$ & $\mathrm{~N}_{2}$ & $\mathrm{~N}_{3}$ & $\mathrm{~N}_{4}$ & $\mathrm{~N}_{5}$ & $\mathrm{~V}_{1}$ & $\mathrm{~V}_{2}$ & $\mathrm{~V}_{3}$ & $\mathrm{~V}_{4}$ & $\mathrm{~V}_{5}$ & $\mathrm{~T}_{1}$ & $\mathrm{~T}_{2}$ & $\mathrm{~T}_{3}$ & $\mathrm{~T}_{4}$ & $\mathrm{~T}_{5}$ \\
\hline Subject 1 & 1450 & 2980 & 2000 & 1980 & 2080 & 19.5 & 38.3 & 52.6 & 76.7 & 92.5 & 23.3 & 29.5 & 24.6 & 30.3 & 24.8 \\
\hline & 1700 & 2950 & 2080 & 3180 & 2100 & 18.5 & 37.1 & 54.3 & 74.6 & 89.5 & 21.1 & 36.4 & 21.4 & 39.2 & 23.2 \\
\hline \multirow{2}{*}{ number } & \multicolumn{15}{|c|}{ test samples of the test subjects } \\
\hline & $\mathrm{N}_{1}$ & $\mathrm{~N}_{2}$ & $\mathrm{~N}_{3}$ & $\mathrm{~N}_{4}$ & $\mathrm{~N}_{5}$ & $\mathrm{~V}_{1}$ & $\mathrm{~V}_{2}$ & $\mathrm{~V}_{3}$ & $\mathrm{~V}_{4}$ & $\mathrm{~V}_{5}$ & $\mathrm{~T}_{1}$ & $\mathrm{~T}_{2}$ & $\mathrm{~T}_{3}$ & $\mathrm{~T}_{4}$ & $\mathrm{~T}_{5}$ \\
\hline Subject 1 & 0.288 & 0.917 & 0.514 & 0.50 & 0.547 & 0.210 & 0.414 & 0.568 & 0.829 & 1.00 & 0.291 & 0.306 & 0.307 & 0.316 & 0.31 \\
\hline Subject2 & 0.390 & 0.905 & 0.547 & 1.00 & 0.555 & 0.206 & 0.414 & 0.606 & 0.833 & 1.00 & 0.263 & 0.455 & 0.267 & 0.491 & 0.29 \\
\hline
\end{tabular}

Table 7. Status value and test sample of the test subjects

Table 8 shows the standard fault identification results of the RBF neural network for two test samples of table 7.

Table 8. Standard fault symptom identification results table for test samples

\begin{tabular}{c|c|c|c|c|c|c|c|c}
\hline number & $y_{1}$ & $y_{2}$ & $y_{3}$ & $y_{4}$ & $y_{5}$ & $y_{6}$ & $y_{7}$ & $y_{8}$ \\
\hline Subject1 & 0.0024 & 0.2704 & 0.2357 & 0.0281 & 0.0645 & 0.063 & 0.7326 & 0.2127 \\
\hline Subject2 & 0.0124 & 0.7092 & 0.1073 & 0.0153 & 0.0382 & 0.1014 & 0.1772 & 0.1117 \\
\hline
\end{tabular}

As the RBF neural network identification result shows, the standard fault symptoms with the highest incidence are $y_{3}=0.745$ for the first object and $y_{8}=0.762$ for the second object. Therefore, the 3rd and 8th symptoms on the 1st and 2nd test subjects can be judged as corresponding standard fault symptoms, respectively. 


\subsection{Efficacy Verification Experiment for Identification of Automatic Transmission fault Symptoms by D-S}

\section{Evidence Theory}

The fuzzy neural network of the 16-28-8 network structure was used with the $E_{1}$ network, and the RBF neural network of the 15-15-8 network structure was used with the $E_{2}$ network. Table 9 shows the identification results of the two neural networks for the test subject.

Table 9. Identification results of the two neural networks

\begin{tabular}{c|c|c|c|c|c|c|c|c|c}
\hline $\begin{array}{c}\text { Test } \\
\text { subject }\end{array}$ & Network & $y_{1}$ & $y_{2}$ & $y_{3}$ & $y_{4}$ & $y_{5}$ & $y_{6}$ & $y_{7}$ & $y_{8}$ \\
\hline \multirow{2}{*}{ Subject 1 } & $E_{1}$ & 0.0072 & 0.1018 & 0.0474 & 0.0431 & 0.3131 & 0.3442 & 0.7835 & 0.3214 \\
\cline { 2 - 10 } & $E_{2}$ & 0.0024 & 0.2704 & 0.2357 & 0.0281 & 0.0645 & 0.0631 & 0.7326 & 0.2127 \\
\hline \multirow{2}{*}{ Subject 2 } & $E_{1}$ & 0.1314 & 0.6017 & 0.0703 & 0.2404 & 0.2813 & 0.0317 & 0.0801 & 0.0516 \\
\cline { 2 - 10 } & $E_{2}$ & 0.0124 & 0.7092 & 0.1073 & 0.0153 & 0.0382 & 0.1014 & 0.1772 & 0.1117 \\
\hline
\end{tabular}

The outputs of two networks $E_{1}, E_{2}$ were as evidence of D-S evidence theory, and a set of it denotes $E=\left\{E_{1}, E_{2}\right\}$. It is constructed an identification set $A=\left\{A_{1}, A_{2}, A_{3}, \cdots A_{t}\right\}$ by using the identification results of the two neural networks. $t$ is the number of total identification states. Since the number of symptoms identified above is 8(Table 2), it is $t=8$. If the number of evidence spaces is $S$, it is $S=2$ when two sub-neural networks are used.

(1) According to the output results of the sub-neural networks $E_{1}$ and $E_{2}$, the degree of approximation, correlation coefficient, and basic probability assignments of each state corresponding to the identification set are calculated, respectively. A possible value of the target output value matrix $\mathrm{Y}$ is an $8 \times 8$ identity matrix.

Table 10 shows the degree of approximation of the state parameters in the output results of the sub-neural networks from Equation (7).

Table 10. Degree of approximation of each state parameters in the output results of sub-neural networks

\begin{tabular}{|c|c|c|c|c|c|c|c|c|c|}
\hline Test & Evidence & \multicolumn{8}{|c|}{ Degree of approximation $\mathrm{d}_{i, \mathrm{j}}$} \\
\hline \multirow{4}{*}{1} & \multirow{2}{*}{$\mathrm{E}_{1}$} & $\mathrm{~d}_{1,1}^{\prime}$ & $\mathrm{d}_{1,2}^{\prime}$ & $\mathrm{d}_{1,3}^{\prime}$ & $\mathrm{d}_{1,4}^{\prime}$ & $\mathrm{d}_{1,5}^{\prime}$ & $\mathrm{d}_{1,6}^{\prime}$ & $\mathrm{d}_{1,7}^{\prime}$ & $\mathrm{d}_{1,8}^{\prime}$ \\
\hline & & 2.9473 & 2.7581 & 2.8669 & 2.8755 & 2.3355 & 2.2733 & 1.3947 & 2.3189 \\
\hline & \multirow{2}{*}{$\mathrm{E}_{2}$} & $\mathrm{~d}_{2,1}^{\prime}$ & $\mathrm{d}_{2,2}^{\prime}$ & $\mathrm{d}_{2,3}^{\prime}$ & $\mathrm{d}_{2,4}^{\prime}$ & $\mathrm{d}_{2,5}^{\prime}$ & $\mathrm{d}_{2,6}^{\prime}$ & $\mathrm{d}_{2,7}^{\prime}$ & $\mathrm{d}_{2,8}^{\prime}$ \\
\hline & & 2.6047 & 2.0687 & 2.1381 & 2.5533 & 2.4805 & 2.4833 & 1.1443 & 2.1841 \\
\hline \multirow{4}{*}{2} & \multirow{2}{*}{$\mathrm{E}_{1}$} & $\mathrm{~d}_{1,1}$ & $\mathrm{~d}_{1,2}^{\prime \prime}$ & $\mathrm{d}_{1,3}$ & $\mathrm{~d}_{1,4}$ & $\mathrm{~d}_{1,5}$ & $\mathrm{~d}_{1,6}$ & $\mathrm{~d}_{1,7}$ & $\mathrm{~d}_{1,8}$ \\
\hline & & 2.2257 & 1.2851 & 2.3479 & 2.0077 & 1.9259 & 2.4251 & 2.3283 & 2.3853 \\
\hline & \multirow{2}{*}{$\mathrm{E}_{2}$} & $\mathrm{~d}_{2,1}$ & $\mathrm{~d}_{2,2}^{\prime \prime}$ & $\mathrm{d}_{2,3}^{\prime \prime}$ & $\mathrm{d}_{2,4}$ & $\mathrm{~d}_{2,5}^{\prime \prime}$ & $\mathrm{d}_{2,6}$ & $\mathrm{~d}_{2,7}^{\prime \prime}$ & $\mathrm{d}_{2,8}$ \\
\hline & & 2.2479 & 0.8543 & 2.0581 & 2.2421 & 2.1963 & 2.0699 & 1.9183 & 2.0493 \\
\hline
\end{tabular}

${ }^{*} \mathrm{~d}_{i, j}, \mathrm{~d}{ }_{i, j}$ : Degree of approximation of each state parameters corresponding to test subject 1 and 2 respectively. 
Table 11 shows the correlation coefficient between each state and the output results of the sub-neuralnetworks from Equation (9).

\begin{tabular}{|c|c|c|c|c|c|c|c|c|c|}
\hline Test & Evidence & \multicolumn{8}{|c|}{ Correlation coefficient $\mathrm{C}_{i}\left(A_{j}\right)$} \\
\hline \multirow{4}{*}{1} & \multirow{2}{*}{$\mathrm{E}_{1}$} & $\mathrm{C}_{1}^{\prime}\left(A_{1}\right)$ & $\mathrm{C}_{1}^{\prime}\left(A_{2}\right)$ & $\mathrm{C}_{1}^{\prime}\left(A_{3}\right)$ & $\mathrm{C}_{1}^{\prime}\left(A_{4}\right)$ & $\mathrm{C}_{1}^{\prime}\left(A_{5}\right)$ & $\mathrm{C}_{1}^{\prime}\left(A_{6}\right)$ & $\mathrm{C}_{1}^{\prime}\left(A_{7}\right)$ & $\mathrm{C}_{1}^{\prime}\left(A_{8}\right)$ \\
\hline & & 0.0993 & 0.1061 & 0.1021 & 0.1018 & 0.1253 & 0.1288 & 0.2099 & 0.1262 \\
\hline & \multirow{2}{*}{$\mathrm{E}_{2}$} & $\mathrm{C}_{2}^{\prime}\left(A_{1}\right)$ & $\mathrm{C}_{2}^{\prime}\left(A_{2}\right)$ & $\mathrm{C}_{2}^{\prime}\left(A_{3}\right)$ & $\mathrm{C}_{2}^{\prime}\left(A_{4}\right)$ & $\mathrm{C}_{2}^{\prime}\left(A_{5}\right)$ & $\mathrm{C}_{2}^{\prime}\left(A_{6}\right)$ & $\mathrm{C}_{2}^{\prime}\left(A_{7}\right)$ & $\mathrm{C}_{2}^{\prime}\left(A_{8}\right)$ \\
\hline & & 0.0993 & 0.1250 & 0.1210 & 0.1013 & 0.1043 & 0.1042 & 0.2261 & 0.1184 \\
\hline \multirow{4}{*}{2} & \multirow{2}{*}{$\mathrm{E}_{1}$} & $\mathrm{C}_{1}\left(A_{1}\right)$ & $\mathrm{C}^{\prime \prime}\left(A_{2}\right)$ & $\mathrm{C}_{1}{ }_{1}\left(A_{3}\right)$ & $\mathrm{C}^{\prime \prime}{ }_{1}\left(A_{4}\right)$ & $\mathrm{C}^{\prime \prime}\left(A_{5}\right)$ & $\mathrm{C}_{1}{ }_{1}\left(A_{6}\right)$ & $\mathrm{C}_{1}\left(A_{7}\right)$ & $\mathrm{C}_{1}{ }_{1}\left(A_{8}\right)$ \\
\hline & & 0.1142 & 0.1979 & 0.1083 & 0.1266 & 0.1320 & 0.1048 & 0.1092 & 0.1066 \\
\hline & \multirow{2}{*}{$\mathrm{E}_{2}$} & $\mathrm{C}_{2}\left(A_{1}\right)$ & $\mathrm{C}_{2}\left(A_{2}\right)$ & $\mathrm{C}_{2}\left(A_{3}\right)$ & $\mathrm{C}_{2}\left(A_{4}\right)$ & $\mathrm{C}_{2}\left(A_{5}\right)$ & $\mathrm{C}_{2}\left(A_{6}\right)$ & $\mathrm{C}_{2}\left(A_{7}\right)$ & $\mathrm{C}_{2}{ }_{2}\left(\mathrm{~A}_{8}\right)$ \\
\hline & & 0.0989 & 0.2604 & 0.1080 & 0.0992 & 0.1012 & 0.1074 & 0.1159 & 0.1085 \\
\hline
\end{tabular}

Table11. Correlation coefficient between each state and the output results of the sub-neural networks ${ }^{*} \mathrm{C}_{i}^{\prime}\left(A_{j}\right), \mathrm{C}_{i}^{\prime \prime}\left(A_{j}\right)$ : Correlation coefficient corresponding totest subject 1 and 2 respectively.

From equations (9) (11), the following parameters can be obtained about 1st subject. If the maximum correlation coefficient between sub-neural networks and each states is called as $\alpha_{i}$, then $\alpha_{1}=0.2099$ and $\alpha_{2}=$ 0.2261. If the distribution coefficient of the correlation coefficient between sub-neural networks and each state is called as $\beta_{\mathrm{i}}$, then $\beta_{1}=0.097$ and $\beta_{2}=0.1155$. The belief coefficient $R_{i}$ of the ith sub-neural network in the whole system is $\mathrm{R}_{1}=0.438$ and $\mathrm{R}_{2}=0.5619$. Table 12 shows the basic probability assignments $m_{1}, m_{2}$ between sub-neural networks and each state according to formulas (12) and (13).

Table 12. Basic probability assignments between two sub-neural networks and each state

\begin{tabular}{|c|c|c|c|c|c|c|c|c|c|c|}
\hline $\begin{array}{c}\text { Test } \\
\text { subject }\end{array}$ & Evidence & \multicolumn{8}{|c|}{ Basic probability assignments, $\mathrm{m}_{\mathrm{i}}\left(A_{j}\right)$} & \multirow{2}{*}{$\begin{array}{c}\text { Belief of } \\
\text { uncertainty } \theta, \\
\mathrm{m}_{\mathrm{i}}(\theta) \\
\mathrm{m}_{1}^{\prime}(\theta)\end{array}$} \\
\hline \multirow{4}{*}{1} & \multirow{2}{*}{$\mathrm{E}_{1}$} & $\mathrm{~m}_{1}^{\prime}\left(A_{1}\right)$ & $\mathrm{m}_{1}^{\prime}\left(A_{2}\right)$ & $\mathrm{m}_{1}^{\prime}\left(A_{3}\right)$ & $\mathrm{m}_{1}^{\prime}\left(A_{4}\right)$ & $\mathrm{m}_{1}^{\prime}\left(A_{5}\right)$ & $\mathrm{m}_{1}^{\prime}\left(A_{6}\right)$ & $\mathrm{m}_{1}^{\prime}\left(A_{7}\right)$ & $\mathrm{m}_{1}^{\prime}\left(A_{8}\right)$ & \\
\hline & & 0.0472 & 0.0505 & 0.0486 & 0.0484 & 0.0596 & 0.0613 & 0.0999 & 0.0601 & 0.5240 \\
\hline & \multirow{2}{*}{$\mathrm{E}_{2}$} & $\mathrm{~m}_{2}^{\prime}\left(A_{1}\right)$ & $\mathrm{m}_{2}^{\prime}\left(A_{2}\right)$ & $\mathrm{m}_{2}^{\prime}\left(A_{3}\right)$ & $\mathrm{m}_{2}^{\prime}\left(A_{4}\right)$ & $\mathrm{m}_{2}^{\prime}\left(A_{5}\right)$ & $\mathrm{m}_{2}^{\prime}\left(A_{6}\right)$ & $\mathrm{m}_{2}^{\prime}\left(A_{7}\right)$ & $\mathrm{m}_{2}^{\prime}\left(A_{8}\right)$ & $\mathrm{m}_{2}^{\prime}(\theta)$ \\
\hline & & 0.0536 & 0.0674 & 0.0653 & 0.0546 & 0.0562 & 0.0562 & 0.1220 & 0.0639 & 0.4604 \\
\hline \multirow{4}{*}{2} & \multirow{2}{*}{$\mathrm{E}_{1}$} & $\mathrm{~m}_{1}\left(A_{1}\right)$ & $\mathrm{m}_{1}\left(A_{2}\right)$ & $\mathrm{m}_{1}\left(A_{3}\right)$ & $\mathrm{m}_{1}\left(A_{4}\right)$ & $\mathrm{m}_{1}\left(A_{5}\right)$ & $\mathrm{m}_{1}\left(A_{6}\right)$ & $\mathrm{m}_{1}\left(A_{7}\right)$ & $\mathrm{m}_{1}{ }_{1}\left(A_{8}\right)$ & $\mathrm{m}_{1}{ }_{1}(\theta)$ \\
\hline & & 0.0476 & 0.0826 & 0.0452 & 0.0528 & 0.0551 & 0.0437 & 0.0455 & 0.0445 & 0.5826 \\
\hline & \multirow{2}{*}{$\mathrm{E}_{2}$} & $\mathrm{~m}_{2}\left(A_{1}\right)$ & $\mathrm{m}_{2}\left(A_{2}\right)$ & $\mathrm{m}_{2}\left(A_{3}\right)$ & $\mathrm{m}_{2}{ }_{2}\left(A_{4}\right)$ & $\mathrm{m}_{2}\left(A_{5}\right)$ & $\mathrm{m}_{2}{ }_{2}\left(A_{6}\right)$ & $\mathrm{m}_{2}^{\prime}\left(A_{7}\right)$ & $\mathrm{m}_{2}\left(A_{8}\right)$ & $\mathrm{m}_{2}(\theta)$ \\
\hline & & 0.0635 & 0.1672 & 0.0694 & 0.0637 & 0.0650 & 0.0690 & 0.0744 & 0.0697 & 0.3578 \\
\hline
\end{tabular}

${ }^{*} \mathrm{~m}_{i}^{\prime}\left(A_{j}\right), \mathrm{m}_{i}{ }_{i}\left(A_{j}\right)$ : Basic probability assignments corresponding to test subject 1 and 2 respectively.

(2) Confirmation of belief interval and Standard fault symptoms

From formulas (14) and (15), the reliability in each identification state is calculated, respectively. Next, it is calculated respectively the belief interval $\left[\mathrm{Bel}\left(\mathrm{A}_{\mathrm{i}}\right), \mathrm{Pl}\left(\mathrm{A}_{\mathrm{i}}\right)\right]$ of each identification system under the global fusion 
action and the corresponding uncertainty probability $\mathrm{m}_{\mathrm{i}}(\theta)$.(Table 13$)$. It too is calculated respectively the belief interval $\left[\mathrm{Bel}\left(\mathrm{A}_{\mathrm{i}}\right), \mathrm{Pl}\left(\mathrm{A}_{\mathrm{i}}\right)\right]$ of each identification system under the single action of the $\mathrm{E}_{1}$ and $\mathrm{E}_{2}$ neural networks and the corresponding uncertainty probability $\mathrm{m}_{\mathrm{i}}(\theta)$. (Table 13 )

Table 13. Belief interval of each state in the output results of two sub-neural networks and result of global fusion system

\begin{tabular}{|c|c|c|c|c|c|c|c|c|c|c|c|}
\hline \multirow{2}{*}{$\begin{array}{c}\text { Test } \\
\text { subject }\end{array}$} & \multirow{2}{*}{ Evidence } & \multicolumn{9}{|c|}{$\operatorname{Bel}_{\left(\mathrm{A}_{\mathrm{j}}\right),} \mathrm{Pl}_{\left(\mathrm{A}_{\mathrm{j}}\right)}$} & \multirow{2}{*}{ Conclusion } \\
\hline & & $\mathrm{A}_{1}$ & $\mathrm{~A}_{2}$ & $\mathrm{~A}_{3}$ & $\mathrm{~A}_{4}$ & $\mathrm{~A}_{5}$ & $\mathrm{~A}_{6}$ & $\mathrm{~A}_{7}$ & $\mathrm{~A}_{8}$ & $\mathrm{~m}_{\mathrm{i}}(\theta)$ & \\
\hline \multirow{3}{*}{1} & $\mathrm{E}_{1}$ & $\begin{array}{l}(0.0472, \\
0.5712)\end{array}$ & $\begin{array}{l}(0.0505, \\
0.5745)\end{array}$ & $\begin{array}{r}(0.0486, \\
0.5726)\end{array}$ & $\begin{array}{l}(0.0484, \\
0.5724)\end{array}$ & $\begin{array}{r}(0.0596 \\
0.5836)\end{array}$ & $\begin{array}{r}(0.0613, \\
0.5853)\end{array}$ & $\begin{array}{r}(0.0999, \\
0.6239)\end{array}$ & $\begin{array}{r}(0.0601, \\
0.5841)\end{array}$ & 0.5240 & uncertainty \\
\hline & $\mathrm{E}_{2}$ & $\begin{array}{l}(0.0536, \\
0.5140)\end{array}$ & $\begin{array}{l}0.0674, \\
0.5278)\end{array}$ & $\begin{array}{r}(0.0653, \\
0.5257)\end{array}$ & $\begin{array}{l}(0.0546, \\
0.5150)\end{array}$ & $\begin{array}{r}0.0562, \\
0.5166)\end{array}$ & $\begin{array}{r}(0.0561, \\
0.5165)\end{array}$ & $\begin{array}{r}0.1220, \\
0.5824)\end{array}$ & $\begin{array}{r}(0.0639, \\
0.5243)\end{array}$ & 0.4604 & uncertainty \\
\hline & $\mathrm{E}_{1 \&} \mathrm{E}_{2}$ & $\begin{array}{l}(0.0898, \\
0.2005)\end{array}$ & $\begin{array}{l}(0.1005 \\
0.2112)\end{array}$ & $\begin{array}{r}(0.0756, \\
0.1863)\end{array}$ & $\begin{array}{l}(0.0724, \\
0.1831)\end{array}$ & $\begin{array}{l}(0.116, \\
0.2267)\end{array}$ & $\begin{array}{r}(0.0967, \\
0.2074)\end{array}$ & $\begin{array}{r}(0.8217, \\
0.9324)\end{array}$ & $\begin{array}{r}(0.0724, \\
0.1831)\end{array}$ & 0.1107 & $\begin{array}{c}\text { 7th } \\
\text { symptom }\end{array}$ \\
\hline \multirow{3}{*}{2} & $\mathrm{E}_{1}$ & $\begin{array}{l}(0.0476 \text {, } \\
0.6302)\end{array}$ & $\begin{array}{l}(0.0826 \\
0.6652)\end{array}$ & $\begin{array}{r}(0.0452, \\
0.6278)\end{array}$ & $\begin{array}{l}(0.0528 \\
0.6354)\end{array}$ & $\begin{array}{r}(0.0551, \\
0.6377)\end{array}$ & $\begin{array}{r}(0.0437, \\
0.6263)\end{array}$ & $\begin{array}{r}(0.0455, \\
0.6281)\end{array}$ & $\begin{array}{r}(0.0445, \\
0.6271)\end{array}$ & 0.5826 & uncertainty \\
\hline & $\mathrm{E}_{2}$ & $\begin{array}{l}(0.0635, \\
0.4213)\end{array}$ & $\begin{array}{l}(0.1672, \\
0.5250)\end{array}$ & $\begin{array}{r}(0.0694, \\
0.4215)\end{array}$ & $\begin{array}{l}(0.0637, \\
0.6354)\end{array}$ & $\begin{array}{r}(0.0650, \\
0.4228)\end{array}$ & $\begin{array}{r}(0.0690, \\
0.4268)\end{array}$ & $\begin{array}{r}(0.0744, \\
0.4322)\end{array}$ & $\begin{array}{r}(0.0697, \\
0.4275)\end{array}$ & 0.3578 & uncertainty \\
\hline & $\mathrm{E}_{1 \&} \mathrm{E}_{2}$ & $\begin{array}{l}(0.0763, \\
0.1844)\end{array}$ & $\begin{array}{l}(0.8394 \\
0.9475)\end{array}$ & $\begin{array}{r}(0.1066, \\
0.2147)\end{array}$ & $\begin{array}{l}(0.1555, \\
0.2636)\end{array}$ & $\begin{array}{r}(0.0893, \\
0.1974)\end{array}$ & $\begin{array}{r}(0.1102, \\
0.2183)\end{array}$ & $\begin{array}{r}(0.0991, \\
0.2072)\end{array}$ & $\begin{array}{r}(0.1235, \\
0.2316)\end{array}$ & 0.1081 & $\begin{array}{c}\text { 2nd } \\
\text { symptom }\end{array}$ \\
\hline
\end{tabular}

According to the D-S evidence theory, it is confirmed the corresponding conclusion under the fusion action with each piece of evidence. According to the decision rule of the D-S evidence theory, only $\operatorname{Bel}\left(\mathrm{A}_{\mathrm{i}}\right)>0.5$ and $\mathrm{m}(\theta)<0.25$ can be confirmed as valid identification results. As shown in Table 13, the results of the test of the two sub-neural networks are uncertain because the decision condition $\left(\operatorname{Bel}\left(A_{i}\right)>0.5\right.$ and $\left.m(\theta)<0.25\right)$ is not satisfied. Under the fusion action of the D-S evidence theory, the test results are as follows. (Table 13). In the first test subject, the belief interval of $A_{7}$ fault was $93.2 \%$ and $m(\theta)$ was 0.11 . Also, in the second test subject, the belief interval of the $A_{2}$ fault was $94.7 \%$ and $m(\theta)$ was 0.1 . Therefore, the decision condition is satisfied. From here, it can be determined that the fault symptom of automatic transmission No. 1 is too high of the shift point(the speed when up-shifts and down-shifts), and the fault symptom of automatic transmission No.2 is impossible to drive range more than 1st shift.

(3) Fault factor discrimination test according to standard fault symptom.

In the test subject, it finds the cause of fault according to the relationship between fault symptoms and corresponding fault factors (Table 3). In Table 3, the factors of maximum fault frequency which correspond to the standard fault symptom are the unqualified accelerator pedal position sensor in the 1st subject and worn forward clutch in the 2nd subject, respectively. As a result of the actual overhaul, it was found that the accelerator pedal position sensor was short-circuited in the 1st automatic transmission. Also, it was found that the forward clutch was already worn in the 2nd automatic transmission. Through this experiment, it was possible to confirm the effectiveness of the fault diagnosis method by identifying standard fault symptoms of automatic transmission.

(4) Analysis of test results

Table 14 and Figure 9 show the identification result of the identification system under fusion action and Identification results by two sub-neural networks for the 1 st test subject. 
Table 14. Identification results of each Identification systems for the 1st test subject

\begin{tabular}{l|l|c|c|c|c|c|c|c|c}
\hline $\begin{array}{l}\text { Identification } \\
\text { system }\end{array}$ & Evidence & $y_{1}$ & $y_{2}$ & $y_{3}$ & $y_{4}$ & $y_{5}$ & $y_{6}$ & $y_{7}$ & $y_{8}$ \\
\hline $\begin{array}{l}\text { Fuzzy neural } \\
\text { network }\end{array}$ & $\mathrm{E}_{1}$ & 0.0072 & 0.1018 & 0.0474 & 0.0431 & 0.3131 & 0.3442 & 0.7835 & 0.3214 \\
\hline RBF neural network & $\mathrm{E}_{2}$ & 0.0024 & 0.2704 & 0.2357 & 0.0281 & 0.0645 & 0.063 & 0.7326 & 0.2127 \\
\hline D-S evidence theory & $\mathrm{E}_{1} \& \mathrm{E}_{2}$ & 0.2005 & 0.2112 & 0.1863 & 0.1831 & 0.2267 & 0.2074 & 0.9324 & 0.1831 \\
\hline
\end{tabular}

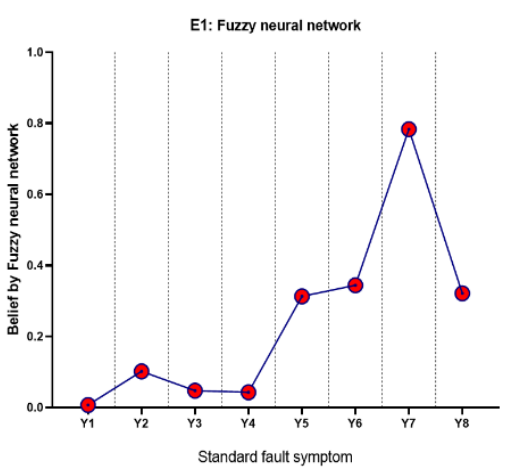

a) Result of Fuzzy neural network

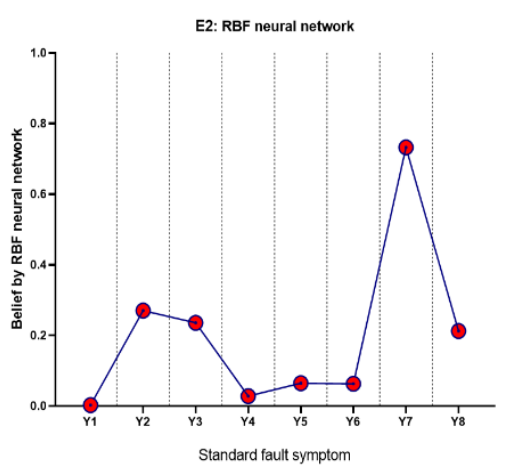

b) Result of RBF neural network

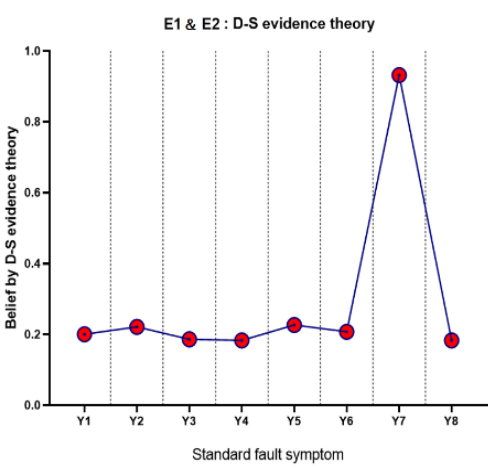

c) Result of D-S evidence theory

Figure 9. Identification results of each Identification systems for the 1st test subject

Table 15 and Figure 10 show the identification result of the identification system under fusion action and identification results by two sub-neural networks for the 2nd test subject.

Table 15. Identification results of each Identification systems for the 2nd test subject

\begin{tabular}{l|l|c|c|c|c|c|c|c|c}
\hline $\begin{array}{l}\text { Identification } \\
\text { system }\end{array}$ & Evidence & $y_{1}$ & $y_{2}$ & $y_{3}$ & $y_{4}$ & $y_{5}$ & $y_{6}$ & $y_{7}$ & $y_{8}$ \\
\hline $\begin{array}{l}\text { Fuzzy neural } \\
\text { network }\end{array}$ & $\mathrm{E}_{1}$ & 0.1314 & 0.6017 & 0.0703 & 0.2404 & 0.2813 & 0.0317 & 0.0801 & 0.0516 \\
\hline RBF neural network & $\mathrm{E}_{2}$ & 0.0124 & 0.7092 & 0.1073 & 0.0153 & 0.0382 & 0.1014 & 0.1772 & 0.1117 \\
\hline D-S evidence theory & $\mathrm{E}_{1} \& \mathrm{E}_{2}$ & 0.1844 & 0.9475 & 0.2141 & 0.2636 & 0.1974 & 0.2183 & 0.2072 & 0.2316 \\
\hline
\end{tabular}

As the experimental results (Table 13 and Figure 8) show, the maximum probability of individual symptoms of the sub-networks on the 1st subject was 78.3\% in the E1 network and 73.2\% in the E2 network. And it reached a maximum of $93 \%$ through information fusion. Conversely, $34.4 \%$ and $27.0 \%$ of the E1 and E2 networks which can be viewed as noise signals, were much smaller to $21.1 \%$ due to the fusion action. As shown in Figure 9, this phenomenon is also the case of the 2nd subject. In this way, it can be seen that the actual cause of the fault can accurately identify the main effect on the occurrence of the fault. 


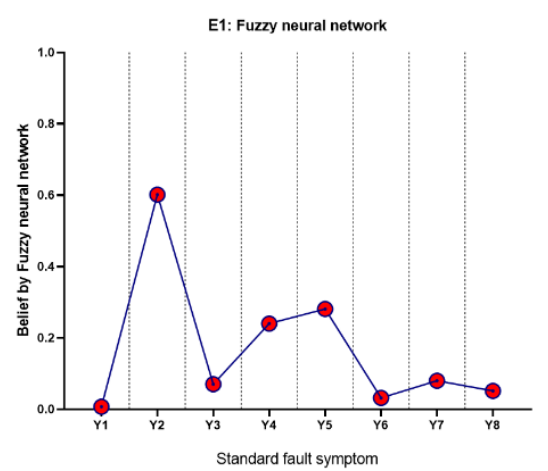

a) Result of Fuzzy neural network

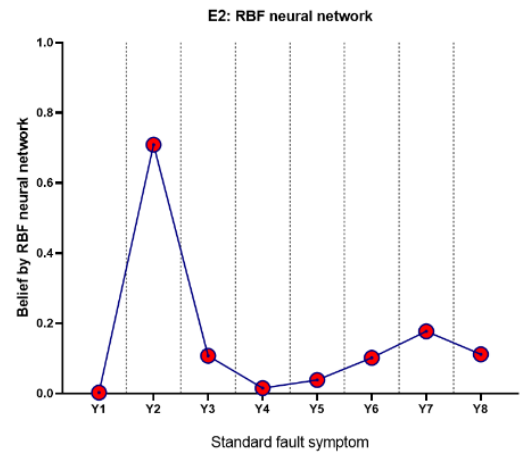

b) Result of RBF neural network

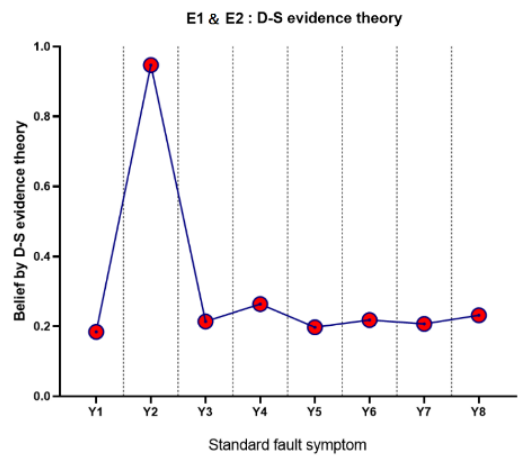

c) Result of D-S evidence theory

Figure 10. Identification results of each Identification systems for the 2nd test subject

\section{Discussion}

In this experiment, in order to verify the effectiveness of the fault symptom identification by the D-S evidence theory, it was conducted identification of the standard fault symptom for different fault phenomena of two 《RE4R01A》 type automatic transmissions so that it was clarified the main cause of the fault. Firstly, fault symptom identification by fuzzy neural network based on driver's appeal and fault symptom identification by RBF neural network based on driving test data were performed. Then, according to the information fusion rule of the D-S evidence theory, the reliability of the fault symptom identification was improved by using the identification results of the previous two fault symptom identification systems. The experiment proved that the result of fault symptom identification by the D-S evidence theory and the actual fault states of the test subjects were consistent with each other. From this, it was proved that the information fusion diagnosis based on the DS evidence theory reduces the coherence caused by non-fault components and enhances the action of the major fault components as much as possible to accurately identify the main action that the actual faulty part gives to the fault occurrence. In other words, it was confirmed that the reliability of the diagnostic system was enhanced and the uncertainty was reduced through the global combination of the sub-neural networks and the D-S evidence theory. In this way, it was verified the validity and feasibility of automatic transmission fault symptom identification based on the D-S evidence theory.

\section{Conclusion}

In this paper, first, qualitative and quantitative identification methods using fuzzy neural network and RBF neural network were introduced in the identification of fault symptoms of automatic transmission. Next, using the identification results of these two neural networks use as the evidence space of the D-S evidence theory it was clarified the methodology for performing global symptom identification. Also the accuracy of this method was verified by an experimental method. In the experiment Firstly, first sub-neural network E1 be used as the fuzzy neural network, the second subneural network E2 be used as RBF neural network, respectively, for preliminary symptom recognition. And then, these outputs of the two sub neural networks are used as the evidence space of D-S evidence theory, so the global diagnosis is carried out. The results show that the test results are consistent with the actual fault symptoms, the success rate of fault diagnosis up to $96.3 \%$. Therefore, it proved that the automatic transmission failure symptom identification method by combining the neural network and the D-S evidence theory is effective. 


\section{REFERENCES}

[1]. Darwish H A, Taalab A M I. Development and implementation of an ANN-based fault diagnosis scheme for generator winding protection J]. IEEE Transactions on Power Delivery, 2001, 16(2):208214

[2]. Aminian F, Aminian M, Collins H W. Analog fault diagnosis of actual circuits using neural networks J]. IEEE Transactions on Instrumentation \& Measurement, 2002, 51(3):544-550.

[3]. Prakash O, Singh V. Signature extraction from acoustic signals and its application for ANN based engine fault diagnosis J]. International Journal of Signal and Imaging Systems Engineering, 2012, 5(3):220- 235

[4]. Witczak M. Advances in model-based fault diagnosis with evolutionary algorithms and neural networks J]. International Journal of Applied Mathematics \& Computer Science, 2006, 16(1):85-99.

[5]. Steiner N Y, Hissel D, P Mo?Otéguy, et al. Application of Fault Tree Analysis to Fuel Cell diagnosisJ]. Fuel Cells, 2012, 12(2):302-309.

[6]. Patan K, Witczak M, Korbicz J. Towards Robustness in Neural Network Based Fault Diagnosis J]. International Journal of Applied Mathematics \& Computer Science, 2008, 18(4):443-454.

[7]. Xie Z, X Liu, Qiaoxiang G U. Research on supplier selection problems based on triangular fuzzy language variables J]. Journal of China University of Metrology, 2019.

[8]. Liu P, Li H. Fuzzy Neural Networks for Storing and Classifying J]. Journal of the Acoustical Society of America, 2014, 95(5):2836-2837.

[9]. Chen Y, Zhen Z, Yu H, et al. Application of Fault Tree Analysis and Fuzzy Neural Networks to Fault Diagnosis in the Internet of Things (IoT) for AquacultureJ]. Sensors, 2017, 17(12):153-.
[10].Han H, Wu X, Liu Z, et al. Data-KnowledgeBased Fuzzy Neural Network for Nonlinear System Identification J]. IEEE Transactions on Fuzzy Systems, 2019, PP (99):1-1.

[11].Zhu W B, Yang H, Jin Y, et al. A Method for Recognizing Fatigue Driving Based on DempsterShafer Theory and Fuzzy Neural Network J]. Mathematical Problems in Engineering, 2017,(2017-02-5),

[12].Meng K, Dong Z Y, Wang D H, et al. A SelfAdaptive RBF Neural Network Classifier for Transformer Fault Analysis J]. IEEE Transactions on Power Systems, 2010, 25(3):1350-1360.

[13].Centeno L, Cesar C, Cristina F, et al. Cognitive radio signal classification based on subspace decomposition and RBF neural networks J]. Wireless Networks, 2018, 24(3):821-831.

[14].Zhang M, Li Y, Cai J , et al. Research on fault diagnosis of diesel engine based on PCA-RBF neural networkJ]. Modern Physics Letters B, 2019.

[15].Xiao F. A new divergence measure for belief functions in D-S evidence theory for multisensor data fusion J]. Information Sciences, 2020, 514:462-483.

[16].Wu X, Wang D, Cao W, et al. A GeneticAlgorithm Support Vector Machine and D-S Evidence Theory Based Fault Diagnostic Model for Transmission Line J]. IEEE Transactions on Power Systems, 2019, 34(99):4186-4194.

[17].Zilong, Jin, Yu, et al. A novel node selection scheme for energy-efficient cooperative spectrum sensing using D-S theory J]. Wireless Networks, 2020, 26(1):269-281.

[18].Gong Y, Su X, Qian H, et al. Research on fault diagnosis methods for the reactor coolant system of nuclear power plant based on D-S evidence theory J]. Annals of Nuclear Energy, 2018, 112(FEB.): 395-399.

[19].Wang Y, Liu Y, Zhang Q. Application of Target Identification in Battlefield Based on Improved 
D-S Evidence Theory J]. Journal of Projectiles, Rockets, Missiles and Guidance, 2015.

[20].Fan X, Zuo M J. Fault diagnosis of machines based on D-S evidence theory. Part 2: Application of the improved D-S evidence theory in gearbox fault diagnosis J]. Pattern Recognition Letters, 2006, 27(5):377-385.

\section{Cite this article as :}

RyongSik O, Jiangwei Chu, Zhenwei Sun, Myongchol Ri, MyongSu Sim, Yongchol Kim, SunGol Ryu, Chunlei Li, CholSong Hwang, KwangBok Kim, " Automatic Transmission Fault Symptom Identification by Apply of Neural Network and D-S Evidence Theory", International Journal of Scientific Research in Science and Technology(IJSRST), Print ISSN : 2395-6011, Online ISSN : 2395-602X, Volume 8, Issue 3, pp.778-799, May-June-2021. Available at doi : https://doi.org/10.32628/IJSRST2183163 